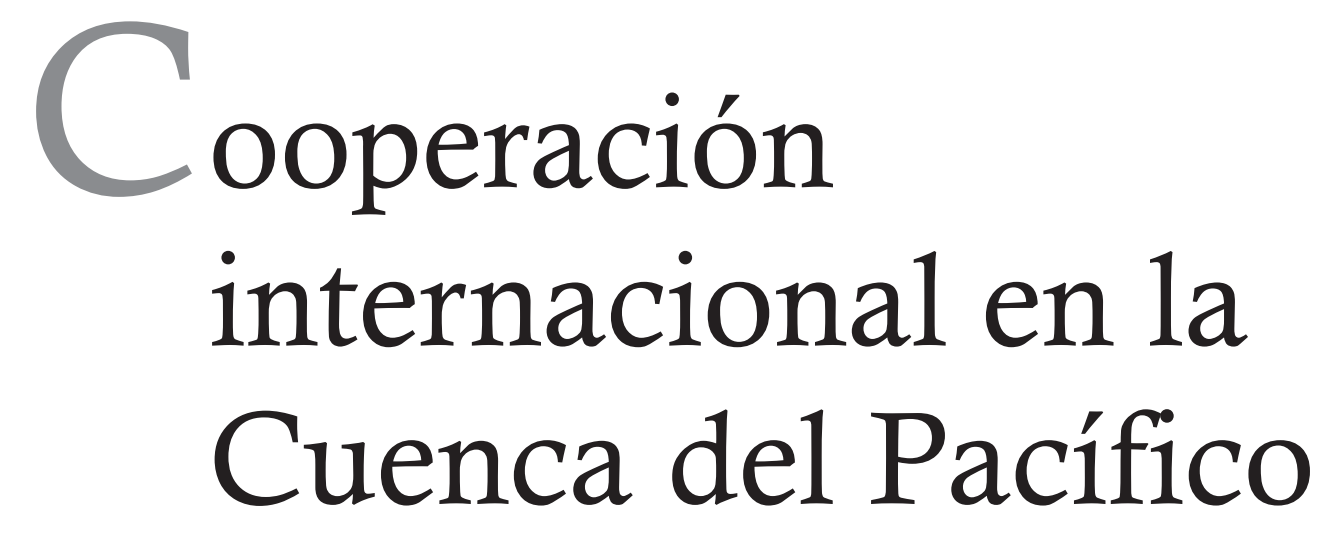

\title{
Las estrategias educativas dentro de APEC y la competitividad internacional: los casos de México y China
}

Introducción

$\mathrm{L}$ a competitividad dentro de APEC comprende diversas variables políticas, económicas y sociales que ayudan a entender mejor la forma en que la pertenencia a esta zona económica beneficia a sus miembros. Este trabajo destaca la educación y su reflejo en la competitividad de un país en los mercados internacionales. No es ningún secreto que en una era donde la tecnología y el conocimiento están muy ligados, la educación desempeña un papel fundamental dentro de la competitividad de cada país.

* Estudiante de la Maestría en Ciencias Sociales de la Universidad de Guadalajara, con especialidad en Estudios Internacionales y del Pacífico.
Actualmente, APEC es la zona económica más dinámica del mundo. Las estadísticas económicas de la región distan mucho de los indicadores de algunas otras regiones del planeta. Dicho dinamismo acarrea consecuencias evidentes en cuanto a la competitividad que las economías deben mantener o satisfacer.

Dentro del contexto competitivo de APEC, la educación juega un papel fundamental en la constitución de un mercado laboral que satisfaga la necesidad de competir en el mercado más dinámico del orbe.

Este trabajo incluye cuatro apartados: a) el APEC, donde presenta una visión general de las características de dicha región económica; b) estandarización de la educación en APEC, que expone la manera en la que la organización demuestra su preocupación por los recursos humanos de 
la zona, así como las acciones y medidas para alcanzar diversos objetivos específicos relacionados con la educación; c) una breve reseña y análisis de las medidas tomadas recientemente por el Estado chino y mexicano encaminadas a mejorar el nivel educativo de su población y volver más competitivo el recurso humano dentro de la economía global; y d) algunos indicadores de México y China relacionados con su situación actual en la competitividad internacional.

APEC

El Mecanismo de Cooperación Económica Asia-Pacífico surgió en 1989 a consecuencia de la creciente interdependencia económica en dicha región. Fue establecido en Canberra, Australia, en noviembre de 1989 durante la Reunión de Ministros de Comercio y Relaciones Exteriores de Australia, Brunei, Canadá, Corea del Sur, Filipinas, Indonesia, Japón, Malasia, Nueva Zelanda, Singapur y Estados Unidos. Dicho encuentro constituyó la I Reunión Ministerial de APEC. La tabla 1 presenta las 21 economías integrantes de APEC.

Tabla 1

Los países integrantes de APEC

\begin{tabular}{lll}
\hline $\begin{array}{l}\text { Australia } \\
\text { Brunei } \\
\text { Darussalam } \\
\text { Canadá }\end{array}$ & $\begin{array}{l}\text { Japón } \\
\text { Corea del Sur }\end{array}$ & $\begin{array}{l}\text { Filipinas } \\
\text { Rusia }\end{array}$ \\
$\begin{array}{l}\text { Chile } \\
\text { China }\end{array}$ & Máxicia & $\begin{array}{l}\text { Singapur } \\
\text { Taipei, China }\end{array}$ \\
Hong Kong & $\begin{array}{l}\text { Pueváa Zelanda Nueva } \\
\text { Guinea }\end{array}$ & $\begin{array}{l}\text { Tailandia } \\
\text { Estados Unidos }\end{array}$ \\
& Perú & Vietnam \\
\hline
\end{tabular}

El objetivo primordial de APEC es impulsar el crecimiento y desarrollo para aumentar los flujos de bienes, servicios, capital y tecnología, en la búsqueda de un régimen comercial abierto en la región así como la reducción de las barreras al intercambio de bienes, tecnología, servicios e inversión y la apertura comercial a través de la acción colectiva. Actualmente, APEC representa el mayor espacio para facilitar el crecimiento económico, la cooperación, el comercio y las inversiones en la región de Asia-Pacífico. Es una organización única en el mundo en cuanto a que representa la unión de tipo intergubernamental cuya operación se basa en compromisos que no implican ningún tipo de vínculo político. $\mathrm{Al}$ contrario de lo que hacen organismos como la Organización Mundial de Comercio, APEC no especifica obligaciones para sus integrantes, puesto que las decisiones que se toman se basan en el consenso y la voluntad individual de los Estados.

Con el transcurso del tiempo la zona de cooperación económica surgida en su i Reunión Ministerial ha logrado consolidarse como una región vital para la expansión de la economía mundial. El impacto de dicha zona de cooperación económica puede apreciarse con los siguientes datos:

1. Representa un mercado de más de 2.5 mil millones de personas.

2. La región tiene un producto regional bruto de $\$ 19$ trillones de dólares.

3. La zona genera $47 \%$ del comercio mundial.

4. Es la región más dinámica, económicamente hablando, porque en sus primeros 10 años de existencia generó cerca de 70\% del crecimiento económico global.

Para tener una idea más clara de los datos anteriores, es necesario conocer los orígenes fundacionales del organismo, el cual, como todo tipo de organización, nació con propósitos bien definidos plasmados en 
políticas a seguir y que se han convertido en los pilares de APEC: a) liberalización del comercio y las inversiones; b) la facilitación del comercio y las inversiones; y c) la cooperación económica y técnica.

De la misma forma, los objetivos específicos para el funcionamiento de dicho acuerdo son los siguientes:

1. Mantener el crecimiento y el desarrollo económico de la región

2. Contribuir al crecimiento económico mundial

3. Reforzar y aprovechar los beneficios de dicho crecimiento

4. Fortalecer el sistema multilateral de comercio

5. Reducir las barreras al comercio de bienes y servicios y a los flujos de inversión.

Como se puede observar, APEC es una experiencia de integración muy ambiciosa que tiene un sello característico: la vanguardia. Tal característica tiene implicaciones importantes en el funcionamiento tanto interno como externo de las economías participantes, debido a que la vanguardia va de la mano de la competitividad y porque la liberación de los mercados desprotege a menos competitivos en el ámbito personal, empresarial, estatal, entre otros.

Debido a lo anterior, hacemos una descripción breve de la manera en que APEC, y algunos de sus miembros como China, trabaja para aumentar la competitividad de sus recursos humanos mediante políticas educativas adecuadas.

\section{La estandarización de la educación en APEC}

Como sus miembros están vinculados y conforman el mercado más fuerte del mundo, APEC decidió estandarizar algu- nos procesos de su sistema empresarial. Las empresas de la región de APEC buscan que los recursos humanos se adapten a la competitividad que exigen los mercados actuales.

El éxito de la integración económica debería reflejarse en la mejoría del nivel de vida de la población. APEC ha propiciado una mayor competencia entre sus países integrantes, lo cual genera mayor competitividad entre sus recursos humanos. Obviamente el nivel entre los países es muy desigual, por ejemplo si comparamos Estados Unidos, Canadá y ciertos países asiáticos con algunos países latinoamericanos. En el caso de México, éste no cuenta con el recurso humano suficientemente capacitado para hacer competitivas a las empresas instaladas en nuestro país, y, por lo tanto, los flujos de inversión que capta el país son menores, ya que el recurso humano eficiente es escaso.

Por eso, los países latinoamericanos están obligados a mejorar sus sistemas educativos y reducir la brecha con los países avanzados. Como dijimos, esta situación genera falta de competitividad y, además, la población tiene menos oportunidades de empleo debido a que no tiene el nivel educativo óptimo para competir en la región de Asia-Pacífico. La carencia de conocimientos hace que las empresas de los países con sistemas educativos deficientes estén en clara desventaja. En el corto plazo tal desventaja conduce a que la integración económica propuesta por APEC sea poco exitosa sobretodo en el mundo globalizado actual.

APEC ha impulsado un programa de desarrollo de recursos humanos con el objetivo de que los países miembros conozcan los requerimientos de la contratación de personal para incentivar la inversión. En 1996 surgió el Proyecto de Ventaja Global a 
través de la Gente que tiene tres objetivos: a) analizar las políticas y prácticas de recursos humanos en las economías de APEC; b) conocer el impacto de lo anterior en la cooperación, el empleo y el reclutamiento en la región; y c) fomentar estudios microeconómicos sobre las políticas y prácticas de recursos humanos en las áreas claves del funcionamiento organizacional/industrial en la región (Zanko, 2003: 77).

La preocupación de la región de APEC por mejorar el recurso humano tiene fines positivos, pero el problema es el desfase que existe entre las economías desarrolladas -Australia, Taiwán, Hong Kong, Japón, Estados Unidos, Brunei, Canadá, Nueva Zelanda, Corea del Sur y Singapur-con respecto a las menos desarrolladas - Indonesia, Malasia, China, Tailandia, Chile, México, Papúa Nueva Guinea, Perú, Filipinas, Rusia y Vietnam-(Zanko, 2003: 78). Esta diferencia educativa propicia que la integración no sea tan positiva para estos últimos países en el corto plazo, puesto que lo importante es la competitividad y la generación de riqueza en el corto plazo.

\section{China y México: dos casos opuestos}

\section{China}

China es un ejemplo sumamente interesante dentro del contexto de los recursos humanos y la educación en APEC. En el año 2000 el presidente de ese país inició la construcción de una fuerza laboral que fuera competitiva en la globalización, impulsado principalmente por la entrada de ese país a la APEC. Dicha construcción se basó en cinco puntos medibles:

1. El establecimiento de nuevas perspectivas de desarrollo y la construcción de las capacidades humanas.
2. La construcción de un sistema de aprendizaje de largo plazo.

3. La utilización de tecnología para el aprendizaje.

4. La promoción de la innovación y la educación en las nuevas generaciones.

5. El reforzamiento de la comunicación y la colaboración internacional (Yang, Zhang y Zhang, 2004: 302).

En su plan quinquenal 2000-2005 China plasmó la importancia del desarrollo de recursos humanos al incluirlo como prioridad nacional. Esta estrategia de desarrollo se basa en cuatro aspectos:

1. La relación entre la calidad de la población y la educación de profesionistas.

2. El entrenamiento de científicos en las áreas naturales y sociales.

3. La relación entre los incentivos materiales y las políticas institucionales que promuevan la innovación.

4. La educación de alto nivel y sistemas de aprendizaje de largo plazo (Yang, Zhang y Zhang, 2004: 302).

A diferencia de los países latinoamericanos como México, China ha tomado las medidas necesarias para que las oportunidades que representa APEC se reflejen en el nivel micro, de una manera muy inteligente. En ese país - al parecer- el estudiante, y futuro empleado o factor productivo, empieza a observar y a sentir los beneficios de la integración económica de China con APEC, lo que seguramente rendirá frutos.

\section{México}

México inició una especie de reforma educativa mediante el Acuerdo Nacional para la Modernización de la Educación. Este acuerdo surgió en 1992, justo dos años antes de que México entrara abiertamente al 
Tratado de Libre Comercio de América del Norte, escenario que volvió necesaria una transformación sustancial en la manera de educar y preparar a la sociedad para enfrentar un reto de tal magnitud.

Antes de 1992 México tenía un esquema de servicios educativos sumamente centralizado. Por ejemplo, en educación básica $74.5 \%$ de 154,000 planteles era operado por el gobierno federal desde la capital del país, lo que obviamente obstruía el funcionamiento eficiente y expedito de los servicios (Guevara y González, 2004: 11).

La descentralización de 1992 permitió la participación de otros sectores de la población y volvió más eficiente, en comparación con el pasado, a la nueva política educativa. En consecuencia, la política educativa se basó en tres prioridades: a) garantizar la equidad en la educación; b) lograr procesos educativos de alta calidad; y c) alcanzar la integración y el funcionamiento óptimo del sistema educativo (Guevara y González, 2004: 12). Los llamados Programas Compensatorios se encargaron de llevar a cabo tales prioridades.

Los Programas Compensatorios son los siguientes:

1. Programa para abatir el rezago en la educación inicial y básica.

2. Programa para la educación comunitaria.

3. Programa de desarrollo humano Oportunidades.

4. Programa Nacional para el Desarrollo de los Pueblos.

5. Programas de Escuelas de Calidad (PEC).

6. Programa Nacional de Fortalecimiento de la Educación Especial y de la Integración Educativa (Guevara y González, 2004: 12-13).

186 MÉXICO YLACUENCA DEL PACÍFICO

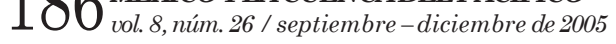

Sin embargo, los programas no establecen claramente la necesidad de lograr recursos humanos competitivos en la economía global, puesto que su interés primordial es educar a la mayoría de la población.

En este sentido, México empezó tarde la reestructuración de su sistema educativo, al menos en el ámbito interno. Pero los avances han sido insuficientes para generar una competitividad real que se refleje en la competitividad internacional de México, y, por lo tanto, se pierden inversiones productivas.

El Acuerdo Nacional para la Modernización de la Educación es un esfuerzo ambicioso, hasta cierto punto. Se ha logrado abatir diversos rezagos en la educación, pero a tal acuerdo le hace falta la adhesión de un programa que, de manera clara, enfrente a ciertos sectores del sistema educativo mexicano a la situación internacional del país, como la competitividad del recurso humano.

México se encuentra en una posición, desde el punto de vista del libre comercio, de privilegio dentro de la economía global, pero las medidas que ha tomado para volverse más competitivo a través de su recurso humano han sido vagas, ${ }^{1}$ al menos mucho más vagas que las acciones tomadas por el Estado chino, por ejemplo.

\section{La competitividad de China y México:} investigación y desarrollo, y su impacto en la cantidad de patentes registradas

En el reporte de APEC de 2005 sobre la situación de sus miembros, aparece un apartado muy interesante relacionado con la educación en cada una de tales economías. APEC define tal apartado como "Indicadores de una economía basada en el conocimiento". Dicho término se relaciona 
con "[...] una economía en donde la producción, distribución y el uso del conocimiento es el principal conductor del crecimiento y la creación de bienestar y empleo a través de todas las industrias" (APEC, 2005: 101). Debemos recordar, tal como se señala en el mismo reporte, que una de las prioridades de APEC es la promoción del crecimiento económico de sus miembros a través de la generación de conocimiento, aspecto que incluye cuatro dimensiones: sistemas de innovación, desarrollo del recurso humano, tecnologías de información y comunicación, y entorno de negocios.

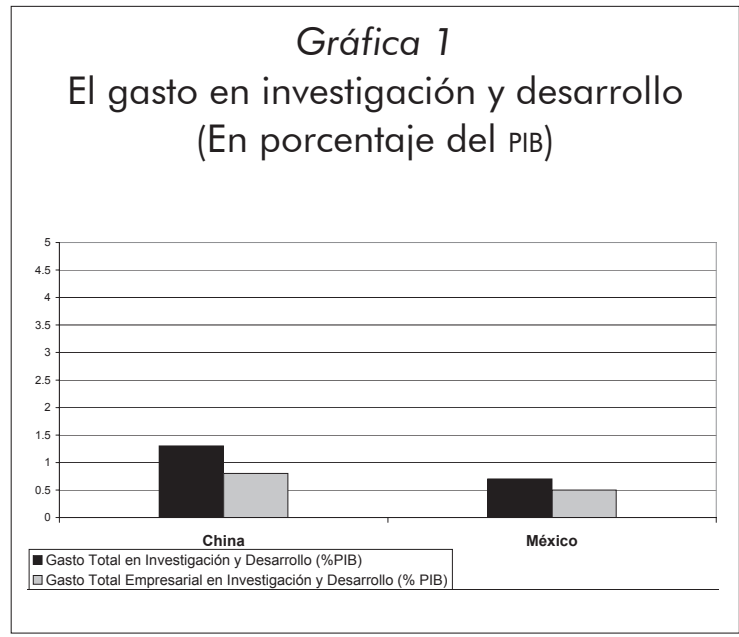

En este artículo usamos los indicadores que nos permiten hacer una buena comparación entre la situación en China y México: el gasto en investigación y desarrollo, y el número de patentes. Esos indicadores son importantes porque las estrategias educativas deben reflejarse en la posición del país en los mercados internacionales, lo que a su vez produce empleos y riqueza para la población. La gráfica 1 muestra el gasto en investigación y desarrollo de ambos países. Ahí se observa que las patentes son una clara consecuencia del nivel de investigación y desarrollo (APEC, 2005: 102).
China tiene un gasto en investigación y desarrollo cercano a 1.5\% del PIB, del cual las empresas generan más de la mitad, lo que denota su actitud competitiva y del gobierno. En México el gasto en investigación y desarrollo se aproxima a $0.5 \%$ del PIB, del cual las empresas privadas generan $75 \%$. Las cifras anteriores se reflejan en el número de patentes de cada país (APEC, 2005: 103).

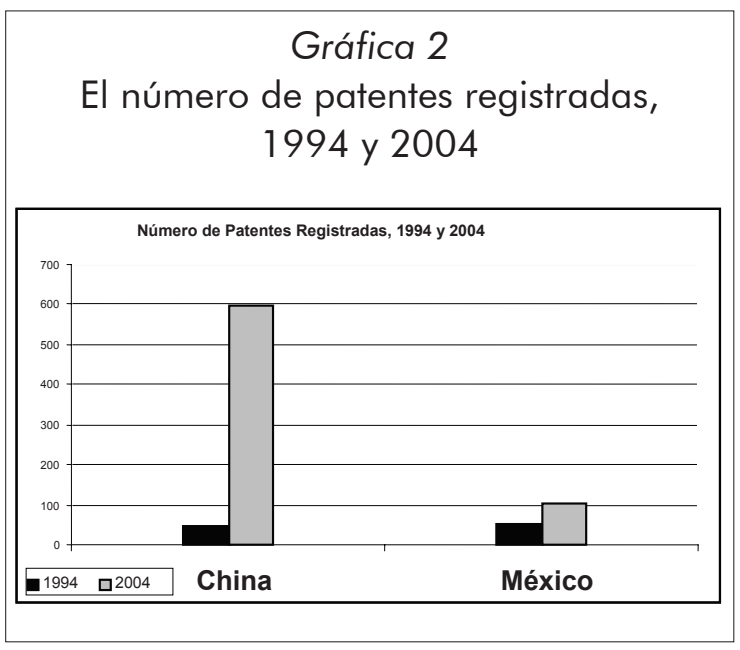

Según la gráfica 2, China registró 48 patentes en 1994 y 597 en 2004, lo que indica el éxito de sus políticas encaminadas a mejorar su competitividad en el mercado internacional a través de la generación de conocimiento (educación). México registró 52 patentes en 1994 y 102 en 2004. Es decir, la cantidad se duplicó en 10 años, lo que podría ser un éxito relativo.

\section{Conclusión}

La experiencia de éxito para las economías miembro en APEC ha resultado ser dispar, especialmente debido a la manera en la que cada una de dichas economías ha enfrentado los retos de la pertenencia a esta zona. Como pudimos observar a través de este texto, la educación juega un papel muy 
importante en dicha confrontación, puesto que un recurso humano competitivo conlleva empresas competitivas, y éstas a su vez, mercados y economías competitivas.

Lo anterior queda claramente ejemplificado en los casos de China y México, países que han ejecutado estrategias distintas para la mejora de su recurso humano. Las medidas de ambos estados distan mucho en cuanto a la agresividad para enfrentar los retos de un mundo globalizado y en constante competencia. El Estado chino entiende, al parecer, la urgencia de tener un mercado laboral competitivo, el Estado mexicano sigue en una pasividad que se refleja en la caída cada vez más drástica de México en los índices de competitividad internacional. De continuar esta tendencia, el desfase entre México y los países asiáticos -Corea del Sur y China, por ejemplo, seguirá creciendo, y seguirá aumentando la pérdida de oportunidades que la pertenencia a APEC representa. my

\section{Referencias bibliográficas}

APEC (2005), Economic Outlook, APEC Economic Committee, Singapur.

Guevara, M. y L. González (2004), "Atraer, formar y retener profesorado de calidad. Actividad de la OECD. Reporte sobre la situación de México.", disponible en http://www.oecd.org.

Yang, B., D. Zhang y M. Zhang (2004), "National Human Resource Development in the People's Republic of China", en Advances in Developing Human Resources, vol. 6, núm. 3, pp. 297-306.

Zanko, M. (2003), "Change and Diversity: HRM Issues and Trends in the Asia-Pacific Region", en Asia Pacific Journal of Human Resources, vol. 41, núm. 1, pp. 75-87.

\section{Notas}

1 Únicamente en México y Filipinas disminuyó el número de personas, entre los 25 y los 34 años de edad, que culminó la preparatoria (APEC, 2005: 103). 